Research paper

\title{
First description of Cryptosporidium hominis GP60 genotype IkA20G1 and Cryptosporidium parvum GP60 genotypes IIaA18G3R1 and IIaA15G2R1 in foals in Brazil
}

\author{
Sandra Valéria Inácio ${ }^{\mathrm{a}, *}$, Giovanni Widmer ${ }^{\mathrm{b}}$, Roberta Lomonte Lemos de Brito ${ }^{\mathrm{c}}$, \\ Anaiza Simão Zucatto ${ }^{a}$, Monally Conceição Costa de Aquino ${ }^{a}$, \\ Bruno César Miranda Oliveira ${ }^{a}$, Alex Akira Nakamura ${ }^{d}$, Luiz da Silveira Neto ${ }^{c}$, \\ João Gabriel Balizardo Carvalho ${ }^{\mathrm{e}}$, Jancarlo Ferreira Gomes ${ }^{\mathrm{f}}$, \\ Marcelo Vasconcelos Meireles ${ }^{\mathrm{d}}$, Katia Denise Saraiva Bresciani ${ }^{\mathrm{a}}{ }^{\mathrm{1}}$ \\ a Universidade Estadual Paulista (UNESP), Faculdade de Medicina Veterinária, Araçatuba, Departamento de Apoio, Produção e Saúde Animal, Araçatuba, \\ São Paulo, Brazil \\ ${ }^{\mathrm{b}}$ Department of Infectious Disease E' Global Health, Cummings School of Veterinary Medicine at Tufts University, North Grafton, MA, USA

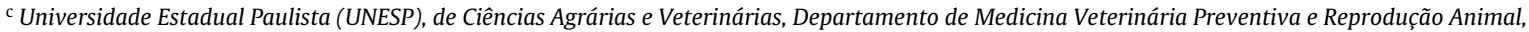 \\ Jaboticabal, São Paulo, Brazil \\ d Universidade Estadual Paulista (UNESP), Faculdade de Medicina Veterinária, Araçatuba, Departamento de Clínica, Cirurgia e Reprodução Animal, \\ Araçatuba, São Paulo, Brazil \\ e Universidade Estadual Paulista (UNESP), Faculdade de Medicina Veterinária, Araçatuba, São Paulo, Brazil \\ f Universidade Estadual de Campinas (Unicamp), Institutos de Biologia e Computação, Campinas, São Paulo, Brazil
}

\section{A R T I C L E I N F O}

\section{Article history:}

Received 23 June 2016

Received in revised form

28 November 2016

Accepted 30 November 2016

\section{Keywords:}

Molecular biology

Equine

Parasite

\begin{abstract}
A B S T R A C T
The present study focuses on Cryptosporidium infections of foals in Brazil. A total of 92 animals of different breeds from 11 farms in the vicinity of Araçatuba in the state of São Paulo, were examined. According to PCR targeting the 18S rRNA gene, Cryptosporidium sp. DNA was detected in $21.7 \%$ (20/92) of foals. Good quality 18S rRNA, actin, HSP70 and gp60 genes nPCR amplicons were obtained from five fecal samples. PCR amplification and sequencing of a fragment of the GP60 sporozoite surface glycoprotein gene revealed C. parvum genotypes IlaA18G3R1, IIaA15G2R1. Interestingly, we also detected in two foals a GP60 genotype related to the human parasite $C$. hominis.
\end{abstract}

(c) 2016 Elsevier B.V. All rights reserved.

\section{Introduction}

Protozoa in the genus Cryptosporidium are important pathogens that cause diarrhea in humans, bovines and others species of animals worldwide (Thompson et al., 2005).

\footnotetext{
* Corresponding author.

E-mail addresses: sandra_byol@yahoo.com.br (S.V. Inácio),

giovanni.widmer@tufts.edu (G.Widmer), rolomonte@gmail.com (R.L.L. de Brito), anaszucatto@hotmail.com (A.S. Zucatto), monallyaquino@hotmail.com

(M.C.C. de Aquino), bruno.9988@hotmail.com (B.C.M. Oliveira), akiravt@gmail.com (A.A. Nakamura), luiz.silveira@gmail.com (L.d.S. Neto), jgbcarvalho@uol.com.br (J.G.B. Carvalho), jgomes@ic.unicamp.br (J.F. Gomes), marcelo@fmva.unesp.br (M.V. Meireles), bresciani@fmva.unesp.br (K.D.S. Bresciani).

1 Address - Rua Clóvis Pestana, 793, Bairro Dona Amélia, CEP 16050-680, Araçatuba, São Paulo, Brazil.
}

Cryptosporidiosis in immunocompetent individual is a selflimiting disease, but in infants, young animals and immunocompromised individulals it may cause a debilitating infection. Cryptosporidiosis typically causes aqueous diarrhea and weight loss (Johnson et al., 1997). In equines, clinical manifestations are rare (Olson et al., 1997).

There are currently 26 named species of Cryptosporidium (Ryan et al., 2014). About 61 genotypes, defined based on host specificity and the sequence of genetic markers (Plutzer and Karanis, 2009) have been reported. Cryptosporidiosis in equines was first described in Arab foals with diarrhea (Snyder et al., 1978). In Brazil, a previous study using nested PCR for detecting Cryptosporidium in equines found no positive animals (Sevá et al., 2010). Equine infections are attributed to $C$. parvum and to what has been named "horse genotype" (Santin, 2013). A recent report described a $C$. hominis infection in a horse from Algeria (Laatamna et al., 2015). The 
detection of Cryptosporidium parasites taxonomically related to $C$. hominis in equines raises new questions about the epidemiology of equine cryptosporidiosis and the zoonotic potential of Cryptosporidium parasites infecting equines. The present study aimed to assess the prevalence of Cryptosporidium infections in foals in Brazil and investigate the taxonomic status of equine isolates.

\section{Materials and methods}

\subsection{Study description}

Fecal samples were collected from all foals one year of age or younger raised on 11 randomly selected farms in the municipalities of Araçatuba, Birigui, Guararapes and Santo Antônio do Aracanguá in the northwestern region of São Paulo State, Brazil (Fig. 1), from November 2010 to March 2011. A total of 92 animals of different breeds were examined. Fifty six foals were male and 36 female, aged from three to 330 days. Foals were allocated to two age groups: $\leq 60$ days and $>60$ days. This study was approved by the Animal Experimentation Ethics Committee of Araçatuba School of Dentistry (FOA), UNESP- Universidade Estadual Paulista Julio de Mesquita Filho (approval $n^{\circ}$. 2009-002165).

Fecal samples were collected directly from the rectal ampulla and stored at $-20^{\circ} \mathrm{C}$ for subsequent DNA extraction and PCR analysis. No microscopic examination or immunofluorescence analyses were performed. To describe the extent of hydration of fecal samples, the following classification was adopted: solid, semisolid, pasty or liquid. Information related to fecal conditions was inserted into a data bank correlating fecal consistency, age and presence of Cryptosporidium DNA. Fecal samples were concentrated by centrifugal sedimentation in water/ether (Meloni and Thompson, 1996) and stored in 5\% dichromate for subsequent DNA extraction. To remove the dichromate prior to DNA extraction, approximately $5 \%$ of the samples was mixed by vortexing and washed multiple times by centrifugation at $2000 \mathrm{~g}$ for $2 \mathrm{~min}$ and resuspending in water.

\subsection{Fecal DNA extraction}

DNA was extracted from 92 foal fecal samples processed as described above using the QIAamp ${ }^{\circledR}$ DNA Stool Mini Kit (Qiagen). Prior to extraction, samples in ASL buffer were frozen in liquid nitrogen and thawed at $95^{\circ} \mathrm{C}$ five times. DNA was eluted in $50 \mu \mathrm{l}$ of $\mathrm{AE}$ buffer and stored at $-20^{\circ} \mathrm{C}$.

\subsection{Molecular characterization}

A fragment of the 18S rRNA gene was amplified by nested PCR (nPCR) as described (Xiao et al., 2000). Cryptosporidium species were identified by sequencing the rRNA PCR products. Samples initially classified as Cryptosporidium based on the 18S rRNA sequence were subjected to nPCR analysis targeting the gp60 gene (Glaberman et al., 2002), the actin gene (Sulaiman et al., 2002), and the HSP70 gene (Morgan et al., 2001). C. parvum DNA was amplified in parallel as a positive nPCR control. Negative control PCRs without added DNA were included throughout.

Good quality 18S rRNA, actin, HSP70 and gp60 genes nPCR amplicons were obtained from five fecal samples. These were purified using a QIAquick ${ }^{\circledR}$ Gel Extraction kit (Qiagen) and sequenced bidirectionaly at the Center for Sequencing and Functional Genomics of UNESP, Jaboticabal Campus. The amplicons were sequenced using the "ABI Prism ${ }^{\circledR}$ Dye Terminator 3.1" protocol (Applied Biosystems) using a ABI 3730XL sequencer (Applied Biosystems). The primers used for sequencing were the same as used for the secondary nPCR. To identify the species and genotypes, the amplicon nucleotide sequences were aligned using Clustal $\mathrm{X}$
Table 1

Origin and genotype of PCR positive foals.

\begin{tabular}{lllll}
\hline Location & 18S & gp60 & actin & HSP70 \\
\hline Araçatuba & C. parvum & IlaA18G3R1 & C. parvum & C. parvum \\
Birigui & C. parvum & IlaA15G2R1 & C. parvum & C. parvum \\
Birigui & C. parvum & IlaA15G2R1 & C. parvum & C. parvum \\
Araçatuba & C. hominis & IkA20G1 & C. hominis & C. hominis \\
Araçatuba & C. hominis & IkA20G1 & C. hominis & C. hominis \\
\hline
\end{tabular}

(Thompson et al., 1997) with sequences of Cryptosporidium spp. downloaded from GenBank. The phylogenetic analysis was performed using MEGA version 5.1 (Kumar et al., 2004). Phylogenetic trees (Fig. 2) were generated using the Neighbor-Joining method based on Kimura's two-parameter model with bootstrap values obtained from 1000 replicates.

\subsection{Nucleotide sequence accession number}

The nucleotide sequences generated in this study were deposited in GenBank TM under accession numbers KT948746, KT948747, КT948748, КТ948749, КТ948750, КT948751 and KT948752.

\subsection{Statistics}

The association between occurrence of Cryptosporidium infection and the variables sex, age and fecal consistency were analyzed with the Chi-square $\left(\chi^{2}\right)$ test or Fisher's Exact test, employing the software SAS and adopting $5 \%$ as significance level.

\section{Results}

According to PCR targeting the 18S rRNA gene, 21.7\% (20/92) of the foals were Cryptosporidium positive. An 18S rRNA amplicon sequence was obtained from 5 of $20 \mathrm{nPCR}$ positive samples. No association between Cryptosporidium infection and sex, age and fecal consistency was found $(P \geq 0.05)$. The actin and HSP70 sequence from a fecal sample of a 10 day old filly was characterisitic of $C$. parvum. Sequencing of a portion of the sporozoite surface glycoprotein GP60 revealed the presence of genotype IIaA18G3R1 in this animal (Fig. 2). The actin and HSP70 sequence from two foals 35 and 75 days of age, respectively, were identified as C. parvum. Sequencing of a portion of the sporozoite surface glycoprotein GP60 revealed the presence of genotype IIaA15G2R1 (Fig. 2). The actin and HSP70 from two samples from foals four and five months of age, respectively, were identified as $C$. hominis. Sequencing of a portion of the sporozoite surface glycoprotein GP60 revealed the presence of genotype IkA20G1 (Fig. 2). The results are summarized in Table 1.

\section{Discussion}

The PCR analysis of fecal DNA originating from 92 foals indicates that Cryptosporidium parasites are present in the horse population we surveyed. The GP60 genotypes Ila (Fig. 2) we found in our study is typically found in zoonotic C. parvum (NazemalhosseiniMojarad et al., 2012). The same Ila genotype was also found foals in New Zealand (Grinberg et al., 2008) indicating that it is geographically widespread in equines. In C. hominis, the most common GP60 genotypes are designated Ia, Ib, Id, Ie and If (Xiao and Ryan, 2007). The GP60 Ik genotype was previously found in equines in Algeria (Laatamna et al., 2015). Because C. hominis typically does not infect animals, it is unclear whether the genotype we and Laatamna et al., 2015 detected is infectious to humans. 


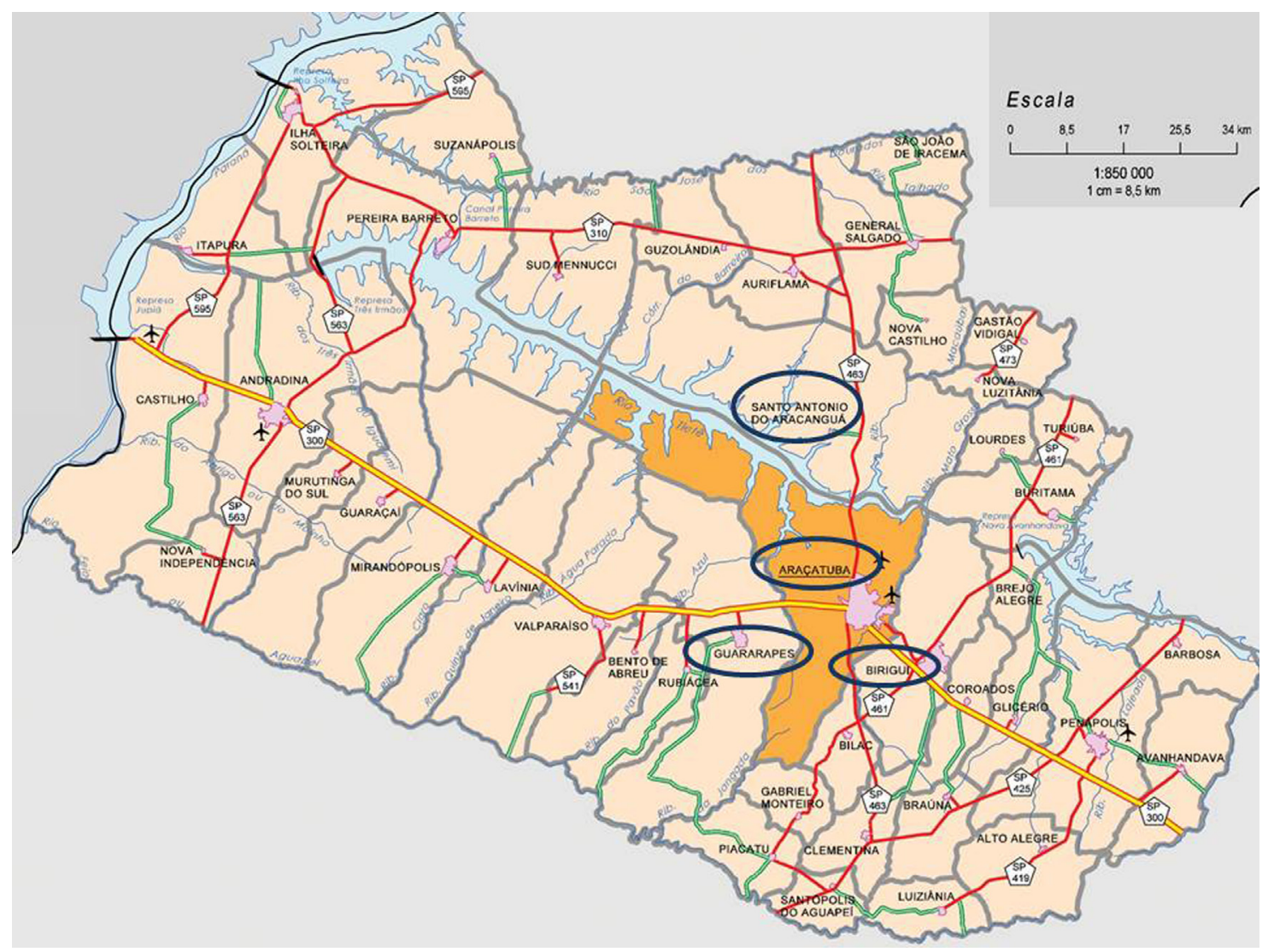

Fig. 1. Map of the District of Aracatuba in Sao Paulo state showing collection sites.

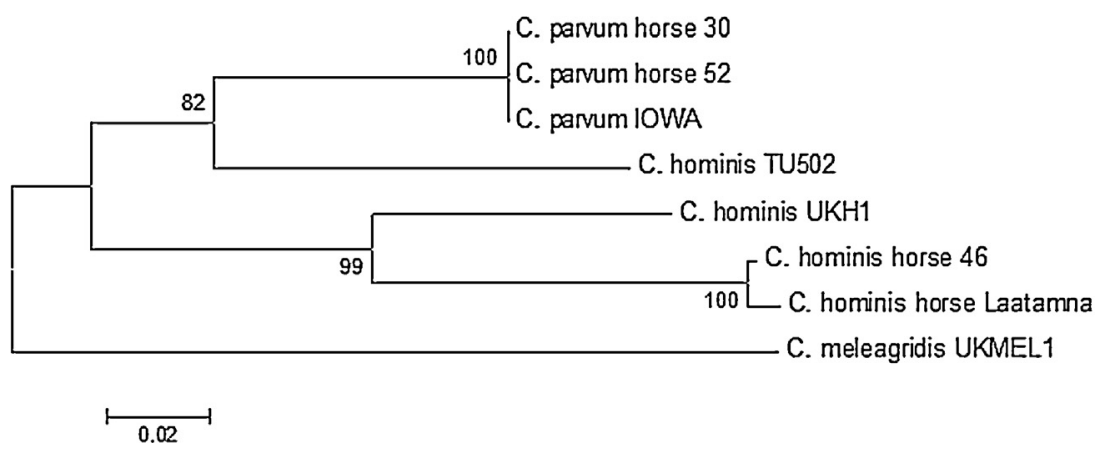

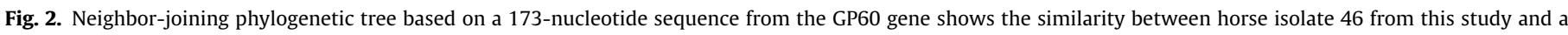
recently described equine isolate from Algeria (Laatamna et al., 2015). Bootstrap values based on 1000 replicates are shown.

The three $C$. parvum positive samples we found were from different farms, however the two samples infected with what appears to be $C$. hominis (Table 1 ) originate from the same property. It is interesting to note that adult horses from the property where C.hominis infected foals were identified drank water from the Baguaçu River in the city of Araçatuba, São Paulo. The river receives untreated urban wastewater (Milani, 2007). Therefore, adult horses may acquire $C$. parvum and possibly $C$. hominis from the river and represent a possible source of infection for foals on this property through direct fecal-oral transmission as Cryptosporidium positive foals drank water from artesian wells. The possibility that untreated urban wastewater can be the source of equine cryptosporidiosis remains to be investigated. Also remains to be elucidated is whether the same $C$. hominis genotype is found in surface water and whether oocysts excreted by there animals are potentially infectious to humans.
C. parvum gp60 genotype IIaA18G3R1 was observed in a 10 days old foal that showed no evidence of diarrhea (Table 1). This genotype was also found in foals with diarrhea in New Zealand (Grinberg et al., 2008). The IlaA15G2R1 genotype was identified in the Czech Republic and in Poland in a 3 year old asymptomatic equine (Wagnerová et al., 2015) and also in fecal samples from the environment in Italy (Galuppi et al., 2015).

The epidemiology of equine cryptosporidiosis is not well studied. Routes of transmission, risk factors, clinical signs, prevalence and economic impact (Veronesi et al., 2010) remain to be characterized. However neonatal infections are frequent and according to two studies occur in about $50 \%$ of the cases of foal diarrhea in (Grinberg et al., 2009; Perrucci et al., 2011).

The identification of a GP60 genotype IkA20G1 (Fig. 2). in our survey may indicate the presence of $C$. hominis or $C$. hominis-like parasites in horses. Interestingly, a very similar GP60 sequence was recently identified in a horse in Algeria (Laatamna et al., 2015) 
(Fig. 2). As found by these authors, in our study the HSP70 sequence of horse isolate 46 was identical to a sequence found in $C$. hominis. In the absence of any biological characterization of Cryptosporidium parasites from horses related to $C$. hominis, it is unknown whether the horse plays a role in the epidemiology of $C$. hominis. The taxonomic significance of this observation remains to be investigated.

\section{Conclusion}

The identification of $C$. hominis-like parasites in foals confirms a previous case from Algeria and indicates that this genotype is widely distributed. This is the first report of infections of foals with C. hominis-like parasites and with C. parvum GP60 genotypes IIaA18G3R1 and IIaA15G2R1 from Brazil.

\section{Conflict of interest}

The authors declare no conflict of interest.

\section{Acknowledgements}

FAPESP (Fundação de Amparo à Pesquisa do Estado de São Paulo) provided financial support to this Project (Process 2010/52542-3). The authors thank the owners and employees of the farms in the Northwestern region of São Paulo State for kindly granting access to their animals for this research. G.W. received financial support from NIAID award 1R15AI122152.

\section{References}

Galuppi, R., Piva, S., Castagnetti, C., Iacono, E., Tanel, S., Pallaver, F., Fioravanti, M.L., Zanoni, R.G., Tampieri, M.P., Caffara, M., 2015. Epidemiological survey on Cryptosporidium in an equine perinatology unit. Vet. Parasitol. 210, 10-18.

Glaberman, S., Moore, J.E., Lowery, C.J., Chalmers, R.M., Sulaiman, I., Elwin, K., Rooney, P.J., Millar, B.C., Dooley, J.S.G., Lal, A.A., Xiao, L., 2002. Three drinking-water-associated Cryptosporidiosis outbreaks, Northern Ireland. Emerg. Infect. Dis. 8, 631-633.

Grinberg, A., Learmonth, J., Kwan, E., Pomroy, W., Villalobos, N.L., Gibson, I., Widmer, G., 2008. Genetic diversity and zoonotic potential of Cryptosporidium parvum causing foal diarrhea. J. Clin. Microbiol. 46, 2396-2398.

Grinberg, A., Pomroy, W.E., Carlslake, H.B., Shi, Y., Gibson, I.R., Drayton, B.M., 2009 A study of neonatal cryptosporidiosis of foals in New Zealand. N. Z. Vet. J. 57, 284-289.

Johnson, E., Atwill, E.R., Filkins, M.E., Kalush, J., 1997. The prevalence of shedding of Cryptosporidium and Giardia spp. based on a single fecal sample collection from each of 91 horses used for backcountry recreation. J. Vet. Diagn. Invest. 9, $56-60$.

Kumar, S., Tamura, K., Nei, M., 2004. MEGA3: integrated software for molecular evolutionary genetics analysis and sequence alignment. Brief. Bioinform. 5, 150-163.
Laatamna, A.E., Wagnerova, P., Sak, B., Kvetonova, D., Xiao, L., Rost, M., McEvoy, J., Saadi, A.R., Aissi, M., Kvac, M., 2015. Microsporidia and Cryptosporidium in horses and donkeys in Algeria: detection of novel Cryptosporidium hominis subtype family (Ik) in a horse. Vet. Parasitol. 208, 135-142.

Milani, R., Diagnóstico da influência da bacia hidrográfica na qualidade da água do Ribeirão Baguaçu (Araçatuba, SP). Ilha Solteira: [s.n.], 200796 p.: il. Dissertação (mestrado) - Universidade Estadual Paulista. Faculdade de Engenharia de Ilha Solteira. Área de conhecimento: Recursos Hídricos e Tecnologias Ambientais, 2007.

Morgan, U.M., Monis, P.T., Xiao, L., Limor, J., Sulaiman, I., Raidal, S., O’Donoghue, P., Gasser, R., Murray, A., Fayer, R., Blagburn, B.L., Lal, A.A., Thompson, R.C., 2001. Molecular and phylogenetic characterisation of Crptosporidium from birds. Int. Parasitol. 31, 289-296.

Nazemalhosseini-Mojarad, E., Feng, Y., Xiao, L., 2012. The importance of subtype analysis of Cryptosporidium spp. In epidemiological investigations of human cryptosporidiosis in Iran and other Mideast countries. Gastroenterol. Hepatol. Bed Bench 5, 67-70.

Olson, M.E., Thorlakson, C.L., Deselliers, L., Morck, D.W., Mcallister, T.A., 1997. Giardia and Cryptosporidium in Canadian farm animals. Vet. Parasitol. 68, 375-381.

Perrucci, S., Buggiani, C., Sgorbini, M., Cerchiai, I., Otranto, D., Traversa, D., 2011. Cryptosporidium parvum infection in a mare and her foal with foal heat diarrhea. Vet. Parasitol. 182, 333-336.

Plutzer, J., Karanis, P., 2009. Genetic polymorphism in Cryptosporidium species: in update. Vet. Parasitol. 165, 187-192.

Ryan, U., Fayer, R., Xiao, L., 2014. Cryptosporidium species in humans and animals: current understanding and research needs. Parasitology 141, 1667-1685.

Santin, M., 2013. Clinical and subclinical infections with Cryptosporidium in animals. N. Z. Vet. J. 61, 1-10.

Sevá, A.P., Funada, M.R., Souza, S.O., Nava, A., Richtzenhain, L.J., Soares, R.M., 2010. Occurrence and molecular characterization of Cryptosporidium spp. isolated from domestic animals in a rural area surrounding Atlantic dry forest fragments in Teodoro Sampaio municipality, State of São Paulo, Brazil. Rev. Bras. Parasitol. Vet. 19, 249-253.

Snyder, S.P., England, J.J., McChesney, A.E., 1978. Cryptosporidiosis in immunodeficient Arabian foals. Vet. Pathol. 15, 12-17.

Sulaiman, I.M., Lal, A.A., Xiao, L., 2002. Molecular phylogeny and evolutionary relationships of Cryptosporidium parasites at the actin locus. J. Parasitol. 88, 388-394.

Thompson, J.D., Gibson, T.J., Plewniak, F., Jeanmougin, F., Higgins, D.G., 1997. The Clustal X windows interface: flexible strategies for multiple sequence alignment aided by quality tools. Nucleic Acids Res. 24, 4876-4882.

Thompson, R.C., Olson, M.E., Zhu, G., Enomoto, S., Abrahamsen, M.S., Hijjawi, N.S., 2005. Cryptosporidium and cryptosporidiosis. Adv. Parasitol. 59, 77-158.

Veronesi, F., Passamonti, F., Cacció, S., Diaferia, M., Fioretti, D.P., 2010. Epidemiological survey on equine Cryptosporidium and Giardia infections in Italy and molecular characterization of isolates. Zoonoses Health Public. 57, 510-517.

Wagnerová, P., Sak, B., McEvoy, J., Rost, M., Matysiak, A.P., Ježková, J., Kváč, M., 2015. Genetic diversity of Cryptosporidium spp. including novel identification of the Cryptosporidium muris and Cryptosporidium tyzzeri in horses in the Czech Republic and Poland. Parasitol. Res. 114, 1619-1624.

Xiao, L., Ryan, U.M., 2007. Molecular epidemiology. In: Fayer, R., Xiao, L. (Eds.), Cryptosporidium and Cryptosporidiosis. CRC Press, Florida, pp. 119-172 (Cap. 5).

Xiao, L., Alderisio, K., Limor, J., Royer, M., Lal, A.A., 2000. Identification of species and sources of Cryptosporidium oocysts in storm waters with a small-subunit rRNA-based diagnostic and genotyping tool. Appl. Environ. Microbiol. 66, 5492-5498. 